\section{Full emission color tuning in luminogens constructed from tetraphenylethene, benzo-2,1,3-thiadiazole and thiophene building blocks $\dagger$}

\author{
Zujin Zhao, ${ }^{a b}$ Chunmei Deng, ${ }^{a}$ Shuming Chen, ${ }^{c}$ Jacky W. Y. Lam, ${ }^{a}$ Wei Qin, ${ }^{a}$ Ping Lu, ${ }^{d}$ \\ Zhiming Wang, ${ }^{d}$ Hoi Sing Kwok, ${ }^{c}$ Yuguang Ma, ${ }^{d}$ Huayu Qiu ${ }^{b}$ and Ben Zhong Tang $* a$ \\ Received 11th May 2011, Accepted 16th June 2011 \\ DOI: $10.1039 / \mathrm{clcc12775f}$
}

Full color luminogens are constructed from tetraphenylethene, benzo-2,1,3-thiadiazole and thiophene building blocks. OLED fabricated using one of the luminogens exhibits orange-red electroluminescence with high luminance and efficiencies of $8330 \mathrm{~cd} \mathrm{~m}^{-2}, 6.1 \mathrm{~cd} \mathrm{~A}^{-1}$ and $3.1 \%$, respectively.

Synthesis of efficient blue, green and red organic materials has been the subject of intense academic research because of their potential applications in full color displays and white lightening devices. However, most dye molecules are highly emissive in the solutions but become weak emitters when fabricated as thin films, which has substantially hampered their practical applications. In 2001, we discovered an opposite phenomenon of aggregation-induced emission (AIE): a group of propeller-like molecules such as silole ${ }^{1,2}$ and tetraphenylethene (TPE) ${ }^{3,4}$ are non-emissive in the solution state but are induced to emit intensely by aggregate formation. Restriction of intramolecular rotation (IMR) has been proposed as the main cause for the AIE phenomenon. ${ }^{5}$ Since then, AIE luminogens with varied molecular structures have been prepared. ${ }^{6}$ Most of the luminogens prepared so far emit blue or green light upon photoexcitation. Indeed, it is desirable to have molecules with different emission colors to meet the needs of various applications. This may be achieved by molecular engineering endeavour via attachment of various substituents to their molecular structures.

Recently, we have prepared a TPE dimer (BTPE, Chart 1), which shows efficient blue photoluminescence (PL) in the solid state and outstanding performance in devices. ${ }^{3 b}$ In this communication, we extend our work on the synthesis of luminescent materials with longer emission wavelengths. We introduced benzo-2,1,3-thiadiazole (TD), a widely used building block for green to red chromophores, ${ }^{7}$ as well as

${ }^{a}$ Department of Chemistry, The Hong Kong University of Science \& Technology (HKUST), Clear Water Bay, Kowloon, Hong Kong, China.E-mail: tangbenz@ust.hk

${ }^{b}$ College of Material, Chemistry and Chemical Engineering,

Hangzhou Normal University, Hangzhou 310036, China

${ }^{c}$ Center for Display Research, HKUST, Hong Kong, China

${ }^{d}$ State Key Laboratory of Supramolecular Structure and Materials,

Jilin University, Changchun 130012, China

$\dagger$ Electronic supplementary information available: Experimental section and performances of the electroluminescence devices. See DOI: $10.1039 / \mathrm{clcc} 12775 \mathrm{f}$ thiophene into BTPE and investigated the PL and electroluminescence (EL) of the resultant molecules.

The TPE-substituted heterocyclics (BTPETD, BTPETTD, BTPEBTTD) are composed of sole benzo-2,1,3-thiadiazole or with directly linked thiophene ring(s) as core and TPE units as peripheries. They are synthesized according to the synthetic routes shown in Scheme S1, details of which can be found in the ESI. $\dagger$ Their thermal properties are investigated by thermogravimetric analysis and differential scanning calorimetry. Results show that they enjoy high thermal stability, starting to lose their weights at $429-495{ }^{\circ} \mathrm{C}$. They are also morphologically stable and show glass-transition temperatures at 130-221 ${ }^{\circ} \mathrm{C}$, which are higher than those of chromophores with similar core and triphenylamine end-cappers. ${ }^{7 c}$

BTPETD, BTPETTD and BTPEBTTD show absorption maxima at $418-510 \mathrm{~nm}$ in their dilute THF solutions (Fig. 1A) associated with intramolecular charge transfer (ICT) from the electron-donating TPE and/or thiophene units to the electronaccepting TD core. ${ }^{7 a-c}$ When their solutions are photoexcited, green to red PL at 538, 592 and $623 \mathrm{~nm}$, respectively, was observed (Fig. 1B). The fluorescence quantum yield $\left(\Phi_{\mathrm{F}}\right)$ of BTPETD in solution estimated using Rhodamine B as standard $\left(\Phi_{\mathrm{F}}=50 \% \text { in ethanol }\right)^{8}$ is $61 \%$, while those of BTPETTD and BTPEBTTD are merely 37 and $25 \%$, respectively, because of stronger ICT effect aroused by the interaction between their thiophene and TD units. It is noteworthy that most conventional luminophores carrying TPE units are practically nonluminescent in the solution state due to the active IMR process, which deactivates the excitons via nonradiative relaxation channels. ${ }^{5 d}$ The reasonably strong emissions of the present luminogens in solutions suggest that the excitons are mainly localized on the TD core, whose decay process is less influenced by the IMR process of TPE units.

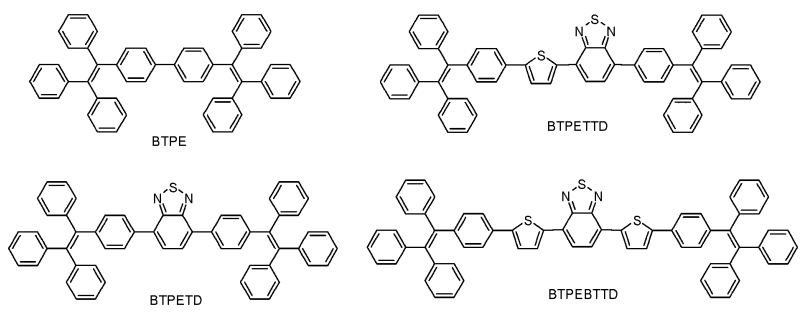

Chart 1 Molecular structures of the TPE-substituted heterocyclics. 

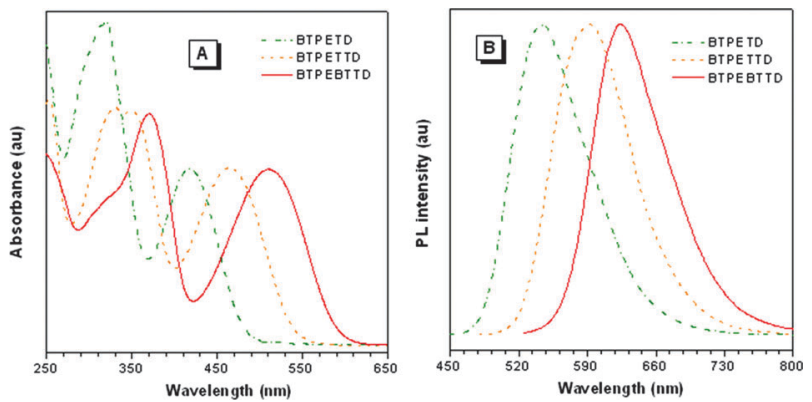

Fig. 1 (A) Absorption and (B) PL spectra of BTPETD, BTPETTD and BTPEBTTD in THF solutions $(10 \mu \mathrm{M})$. Excitation wavelength: $350 \mathrm{~nm}$.

The BTPETD film emits at $539 \mathrm{~nm}$ with a higher $\Phi_{\mathrm{F}}$ value of $89 \%$, demonstrative of a novel phenomenon of aggregationenhanced emission. The film emissions of BTPETTD and BTPEBTTD are observed at 600 and $661 \mathrm{~nm}$, which are 8 and $38 \mathrm{~nm}$ red-shifted from those of the solutions, respectively. Whereas BTPETTD exhibits a $\Phi_{\mathrm{F}}$ value of $55 \%$, the fluorescence quantum yield of BTPEBTTD is hard to be determined due to the mismatch of its excitation wavelength with that of the instrument. However, through visual observation of its solution and solid powders under UV illumination, we believe that BTPEBTTD shows weaker emission in the condensed phase (Fig. 2C). The large red-shift in the emission of BTPEBTTD in the solid state is probably due to the thiophene rings, which relieve the steric effect imposed by the TPE units on the TD core. This allows the BTPEBTTD molecules to stack in a cross-like pattern and consequently leads to stronger intermolecular interactions and bathochromic shift in the PL spectum (Fig. 2A). ${ }^{7 a, e}$

To better understand the photophysical properties of BTPETD, BTPETTD and BTPEBTTD, theory calculations using the density functional (DFT) with the B3LYP hybrid functional at the basis set level of 6-31G (d) are carried out.
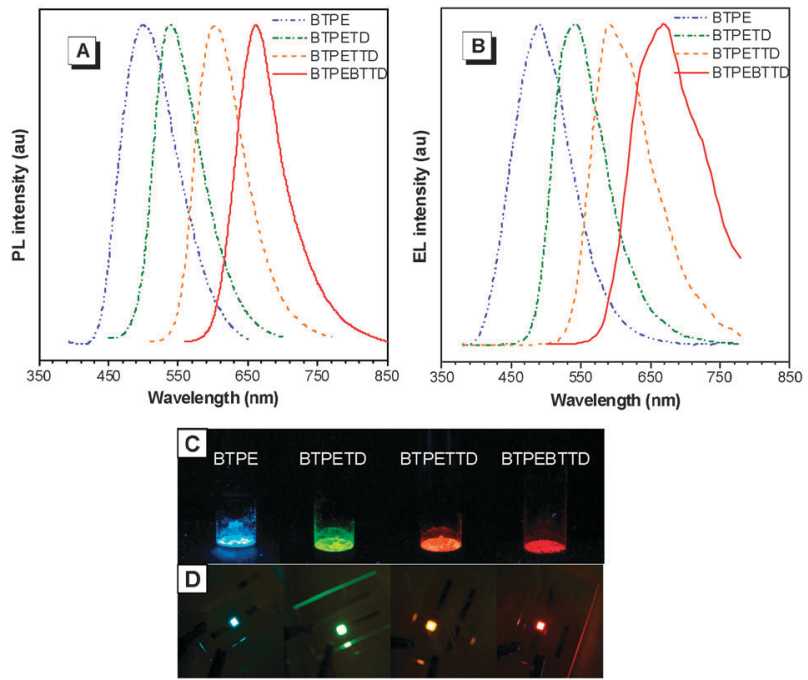

Fig. 2 (A) PL spectra of solid thin films of BTPETD, BTPETTD and BTPEBTTD and (B) their EL spectra. Photographs of their powders taken under illumination of a UV lamp and their EL devices are given in (C) and (D).
Their optimized molecular structures and HOMO and LUMO plots are shown in Fig. 3. The HOMO of BTPETD is dominated by the orbitals from the TD core and the two peripheral TPE units. The TPE units are also conjugated with the thiophene and TD rings in BTPETTD and BTPEBTTD but the contribution of their phenyl rings to the HOMO energy levels becomes smaller. The LUMO plots of all the luminogens are similar and they are dominated by the orbitals from the central TD ring. The HOMO energy levels of BTPETD, BTPETTD and BTPEBTTD are calculated to be -5.31 , -5.12 and $-5.00 \mathrm{eV}$, respectively (Table 1), while their LUMO's fall in the range from -2.47 to $-2.72 \mathrm{eV}$. Although the calculated energy band gaps (2.84-2.28 eV) are somewhat larger than the experimental values estimated from the onset absorption wavelengths, the theoretical study nicely explains the bathochromic shifts in the absorption and emission of BTPETTD and BTPEBTTD from those of BTPETD.

The EL properties of the TPE-substituted heterocyclics are investigated in multilayer organic light-emitting diodes (OLEDs) with a configuration of ITO/NPB $(60 \mathrm{~nm}) /$ emitter $(20 \mathrm{~nm}) / \mathrm{TPBi}(10 \mathrm{~nm}) / \mathrm{Alq}_{3}(30 \mathrm{~nm}) / \mathrm{LiF}(1 \mathrm{~nm}) / \mathrm{Al}(100 \mathrm{~nm}){ }^{9}$ In these EL devices, BTPETD, BTPETTD and BTPEBTTD serve as emitters and $\mathrm{NPB}, \mathrm{TPBi}$ and $\mathrm{Alq}_{3}$ work as holetransporting, hole-blocking and electron-transporting layers, respectively. Fig. 2B and Fig. S1 (ESI $\dagger$ ) show their EL spectra and performance curves and Table 2 summarizes the EL data. The EL's of BTPETD, BTPETTD and BTPEBTTD are observed at 540-668 nm, which are close to their film PL's. The device based on BTPETD shows a maximum luminance $\left(L_{\max }\right)$ of $13540 \mathrm{~cd} \mathrm{~m}^{-2}$, a maximum current efficiency $\left(\eta_{\mathrm{C}, \max }\right)$ of $5.2 \mathrm{~cd} \mathrm{~A}^{-1}$, and a maximum external quantum efficiency $\left(\eta_{\text {ext,max }}\right)$ of $1.5 \%$. Even better performances are observed in BTPETTD. The EL device of BTPETTD radiates orange-red EL brilliantly with $L_{\max }, \eta_{\mathrm{C}, \max }$ and $\eta_{\text {ext,max }}$ of $8330 \mathrm{~cd} \mathrm{~m}^{-2}$, $6.4 \mathrm{~cd} \mathrm{~A}^{-1}$ and $3.1 \%$, respectively, which are much higher than the values attained by most non-doped fluorescent red OLEDs. ${ }^{7,10,11}$ BTPEBTTD exhibits red EL at $668 \mathrm{~nm}$. Although the $L_{\max }$ and $\eta_{\text {ext,max }}$ achieved are merely $1640 \mathrm{~cd} \mathrm{~m}^{-2}$ and $1.0 \%$, such values are already quite high when compared with the previous results. ${ }^{11}$ Combined with BTPE, the EL emissions of these luminogens cover from blue to red spectral regions

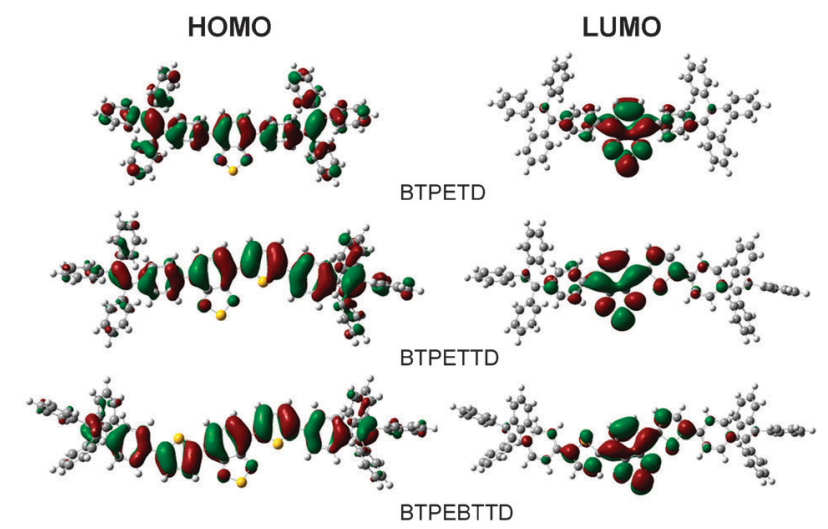

Fig. 3 Optimized molecular structures and molecular orbital amplitude plots of HOMO and LUMO energy levels of the TPE-substituted heterocyclics calculated using the B3LYP/6-31G(d) basis set. 
Table 1 Optical and thermal properties and energy levels of BTPETD, BTPETTD and BTPEBTTD ${ }^{a}$

\begin{tabular}{|c|c|c|c|c|c|c|c|c|c|c|}
\hline & \multirow{2}{*}{$\begin{array}{l}\lambda_{\mathrm{abs}} / \mathrm{nm} \\
\text { Soln }\end{array}$} & \multicolumn{2}{|c|}{$\underline{\lambda_{\mathrm{em}} / \mathrm{nm}}$} & \multicolumn{2}{|c|}{$\Phi_{\mathrm{F}}(\%)$} & \multirow[b]{2}{*}{$E_{\mathrm{opt}} / \mathrm{eV}$} & \multirow[b]{2}{*}{$\mathrm{HOMO} / \mathrm{eV}$} & \multirow[b]{2}{*}{ LUMO/eV } & \multirow[b]{2}{*}{$E_{\text {gap }} / \mathrm{eV}$} & \multirow[b]{2}{*}{$T_{\mathrm{g}} / T_{\mathrm{d}} /{ }^{\circ} \mathrm{C}$} \\
\hline & & Soln & Film & $\operatorname{Soln}^{b}$ & Film $^{c}$ & & & & & \\
\hline BTPETD & 418 & 538 & 539 & 61 & 89 & 2.55 & -5.31 & -2.47 & 2.84 & $130 / 429$ \\
\hline BTPETTD & 464 & 592 & 600 & 37 & 55 & 2.31 & -5.12 & -2.61 & 2.51 & $139 / 495$ \\
\hline BTPEBTTD & 510 & 623 & 661 & 25 & - & 2.05 & -5.00 & -2.72 & 2.28 & $221 / 486$ \\
\hline
\end{tabular}

${ }^{a}$ Abbreviation: Soln $=$ solution $(10 \mu \mathrm{M}$ in THF $), \lambda_{\mathrm{abs}}=$ absorption maximum, $\lambda_{\mathrm{em}}=$ emission maximum, $\Phi_{\mathrm{F}}=$ fluorescence quantum yield, $E_{\mathrm{opt}}=$ energy gap obtained from absorption spectrum, HOMO $=$ highest occupied molecular orbitals, LUMO $=$ lowest unoccupied molecular orbitals, $E_{\text {gap }}=$ theoretically calculated energy gap, $T_{\mathrm{g}}=$ glass-transition temperature, $T_{\mathrm{d}}=$ onset decomposition temperature. ${ }^{b}$ Estimated using Rhodamine $\mathrm{B}$ as standard $\left(\Phi_{\mathrm{F}}=50 \%\right.$ in ethanol). ${ }^{c}$ Measured by integrating sphere.

Table 2 EL performances of the TPE-substituted heterocyclics ${ }^{a}$

\begin{tabular}{|c|c|c|c|c|c|c|}
\hline & $\lambda_{\mathrm{EL}} / \mathrm{nm}$ & $V_{\text {on }} / \mathrm{V}$ & $L_{\max } / \mathrm{cd} \mathrm{m}^{-2}$ & $\eta_{\mathrm{P}, \max } / \mathrm{lm} \mathrm{W}^{-1}$ & $\eta_{\mathrm{C}, \max } / \mathrm{cd} \mathrm{A}^{-1}$ & $\eta_{\text {ext,max }}(\%)$ \\
\hline BTPETD & 540 & 3.9 & 13540 & 3.0 & 5.2 & 1.5 \\
\hline BTPETTD & 592 & 5.4 & 8330 & 2.9 & 6.4 & 3.1 \\
\hline BTPEBTTD & 668 & 4.4 & 1640 & 0.5 & 0.4 & 1.0 \\
\hline
\end{tabular}

${ }^{a}$ Device configuration: ITO/NPB $(60 \mathrm{~nm}) /$ emitter $(20 \mathrm{~nm}) / \mathrm{TPBi}(10 \mathrm{~nm}) / \mathrm{Alq}_{3}(30 \mathrm{~nm}) / \mathrm{LiF}(1 \mathrm{~nm}) / \mathrm{Al}(100 \mathrm{~nm})$. Abbreviation: $\lambda_{\mathrm{EL}}=\mathrm{EL}$ maximum, $V_{\mathrm{on}}=$ turn-on voltage defined at $1 \mathrm{~cd} \mathrm{~m}^{-2}, L_{\max }=$ maximum luminance, $\eta_{\mathrm{P}, \text { max }}=$ maximum power efficiency, $\eta_{\mathrm{C}, \text { max }}=$ maximum current efficiency, and $\eta_{\text {ext,max }}=$ maximum external quantum efficiency.

(Fig. 2D), indicating that they are of potential applications in white OLEDs. Preliminary results show that efficient white OLEDs are fabricated using BTPETTD as one of the emitting components. ${ }^{12}$ For example, a non-doped bilayer white OLED constructed using BTPETTD and DDPi as red and blue emitters, respectively, shows an efficiency of $4.2 \mathrm{~cd} \mathrm{~A}^{-1}$ at $1000 \mathrm{~cd} \mathrm{~m}^{-2}$, 1931 Commision International de L'Eclairage coordinates of $(0.31,0.31)$ and a high color rendering index of 92 over a wide range of driving voltages. ${ }^{12 b}$

In summary, new luminogens with tunable optical properties are constructed from TPE, benzo-2,1,3-thiadiazole and thiophene. These molecules emit intense PL in both solution and solid states. Non-doped OLEDs utilizing them as emitters are fabricated, which give blue to red EL in high efficiencies, suggesting that they are promising candidates for full color displays and white OLEDs.

The work reported in this paper was partially supported by the Research Grants Council of Hong Kong (603509, HKUST13/CRF/08 and HKUST2/CRF/10), the University Grants Committee of Hong Kong (AoE/P-03/08), and the National Natural Science Foundation of China (20974028). Z.J.Z. acknowledges the financial support from the Initial Funding of Hangzhou Normal University (HSQK0085) and Natural Science Foundation of Zhejiang Province (Y4110331).

\section{Notes and references}

1 (a) J. Luo, Z. Xie, J. W. Y. Lam, L. Cheng, H. Chen, C. Qiu, H. S. Kwok, X. Zhan, Y. Liu, D. Zhu and B. Z. Tang, Chem. Commun., 2001, 1740; (b) Y. Hong, J. W. Y. Lam and B. Z. Tang, Chem. Commun., 2009, 4332.

2 (a) Z. Zhao, Z. Wang, P. Lu, C. Y. K. Chan, D. Liu, J. W. Y. Lam, H. H. Y. Sung, I. D. Williams, Y. Ma and B. Z. Tang, Angew. Chem., Int. Ed., 2009, 48, 7608; (b) Z. Li, Y. Dong, J. W. Y. Lam, J. Sun, A. Qin, M. Häußler, Y. Dong, H. H. Y. Sung, I. D. Williams, H. S. Kwok and B. Z. Tang, Adv. Funct. Mater., 2009, 19, 1 .
3 (a) Z. Zhao, J. W. Y. Lam and B. Z. Tang, Curr. Org. Chem., 2010, 14, 2109; (b) Z. Zhao, S. Chen, X. Shen, F. Mahtab, Y. Yu, P. Lu, J. W. Y. Lam, H. S. Kwok and B. Z. Tang, Chem. Commun., 2010, 46, 686.

4 (a) V. S. Vyas and R. Rathore, Chem. Commun., 2010, 46, 1065; (b) W. Wang, T. Lin, M. Wang, T.-X. Liu, L. Ren, D. Chen and S. Huang, J. Phys. Chem. B, 2010, 114, 5983.

5 (a) Z. Li, Y. Dong, B. Mi, Y. Tang, M. Häußler, H. Tong, Y. Dong, J. W. Y. Lam, Y. Ren, H. H. Y. Sun, K. S. Wong, P. Gao, I. D. Williams, H. S. Kwok and B. Z. Tang, J. Phys. Chem. B, 2005, 109, 10061; (b) S. Dong, Z. Li and J. Qin, J. Phys. Chem. B, 2009, 113, 434; (c) V. S. Vyas and R. Rathore, Chem. Commun., 2010, 46, 1065; (d) V. S. Vyas, M. Banerjee and R. Rathore, Tetrahedron Lett., 2009, 50, 6159.

6 (a) Z. Zhao, S. Chen, J. W. Y. Lam, P. Lu, Y. Zhong, K. S. Wong, H. S. Kwok and B. Z. Tang, Chem. Commun., 2010, 46, 2221; (b) Z. Zhao, P. Lu, J. W. Y. Lam, Z. Wang, C. Y. K. Chan, H. H. Y. Sung, I. D. Williams, Y. Ma and B. Z. Tang, Chem. Sci., $2011,2,672$.

7 (a) J. Huang, Q. Liu, J.-H. Zou, X.-H. Zhu, A.-Y. Li, J.-W. Li, S. Wu, J. Peng, Y. Cao, R. Xia, D. D. C. Bradley and J. Roncali, Adv. Funct. Mater., 2009, 19, 2978; (b) Z. H. Li, M. S. Wong, H. Fukutani and Y. Tao, Chem. Mater., 2005, 17, 5032; (c) K. R. J. Thomas, J. T. Lin, M. Velusamy, Y.-T. Tao and C.-H. Chuen, $A d v$. Funct. Mater., 2004, 14, 83; (d) Y. Zhou, Q. He, Y. Yang, H. Zhong, C. He, G. Sang, W. Liu, C. Yang, F. Bai and Y. Li, Adv. Funct. Mater., 2008, 18, 3299; (e) R. D. Xia, G. Heliotis, Y. B. Hou and D. D. C. Bradley, Org. Electron., 2003, 4, 165.

8 J.-H. Wang and Y.-Q. Shen, Adv. Mater. Opt. Electron., 1999, 9, 129.

9 ITO $=$ indium tin oxide; NPB $=N, N^{\prime}-\operatorname{di}\left(1\right.$-naphthyl) $N, N^{\prime}$ diphenyl-benzidine; TPBi $=1,3,5$-tris $(N$-phenylbenzimidazol-2yl)benzene; $\mathrm{Alq}_{3}=$ tris(8-hydroxyquinolinolato)aluminium.

10 (a) S. Chen, X. Xu, Y. Liu, G. Yu, X. Sun, W. Qiu, Y. Ma and D. Zhu, Adv. Funct. Mater., 2005, 15, 1541; (b) X. Xu, G. Yu, S. Chen, C. Di and Y. Liu, J. Mater. Chem., 2008, 18, 299.

11 (a) H.-C. Yeh, L.-H. Chan, W.-C. Wu and C.-T. Chen, J. Mater. Chem., 2004, 14, 1293; (b) W.-C. Wu, H.-C. Yeh, L.-H. Chan and C.-T. Chen, Adv. Mater., 2002, 14, 1072.

12 (a) S. Chen, Z. Zhao, B. Z. Tang and H. S. Kwok, J. Phys. D: Appl. Phys., 2010, 43, 095101; (b) S. Chen, Z. Zhao, Z. Wang, P. Lu, Z. Gao, Y. Ma, B. Z. Tang and H. S. Kwok, J. Phys. D: Appl. Phys., 2011, 44, 145101. 